\title{
The role of perioperative oral nutritional supplementation in elderly patients after hip surgery
}

\author{
Ming Liu',* \\ Jing Yang ${ }^{2, *}$ \\ $\mathrm{XiYu^{3 }}$ \\ Xiao Huang' \\ Sushan Vaidya' \\ Fuguo Huang' \\ Zhou Xiang' \\ 'Department of Orthopedics, West \\ China Hospital, Sichuan University, \\ Chengdu, Sichuan Province, \\ 2Department of Pain, Xiamen No 2 \\ Hospital, Xiamen, Fujian Province, \\ ${ }^{3}$ West China School of Medicine, \\ Sichuan University, Chengdu, Sichuan \\ Province, People's Republic of China \\ *These authors contributed equally \\ to this work
}

This article was published in the following Dove Press journal:

Clinical Interventions in Aging

II May 2015

Number of times this article has been viewed

Background: The effect of perioperative oral nutritional supplementation (ONS) on elderly patients after hip surgery remains controversial. This study intended to ascertain whether perioperative ONS is beneficial for the rehabilitation of elderly patients after hip surgery.

Materials and methods: We searched databases including PubMed, Embase, and the Cochrane Central Register of Controlled Trials for articles published up to May 2014. Randomized controlled trials of ONS for elderly patients after hip surgery were included.

Results: The combined trials showed that ONS had a positive effect on the serum total protein $(P<0.00001)$ and led to a significantly decreased number of complications $(P=0.0005)$. Furthermore, data from the infection subgroups showed significant decreases in wound infection $(P=0.02)$, respiratory infection $(P=0.04)$, and urinary tract infection $(P=0.03)$. Clinical observation suggests that the intervention may improve the level of serum albumin, although the data did not reach statistical significance $(P=0.48)$. Regarding mortality, there was no significant statistical difference between the intervention group and the control $(P=0.93)$.

Conclusion: Based on the evidence available, this meta-analysis is consistent with the hypothesis that perioperative ONS can help elderly patients recover after hip surgery and reduce complications.

Keywords: oral nutrition, elderly patient, hip surgery, meta-analysis

\section{Introduction}

The incidence of hip fracture in elderly people will reach $11.9 \%$ by the end of 2030 with life extension and increasing social activities such as travelling, riding (bicycle and motorcycle), dancing, and so on. ${ }^{1-5}$ Nutritional status is an important influencing factor for early postoperative rehabilitation. However, a variety of factors, such as pre-fracture nutritional status, underlying diseases, and wound stress induce a high incidence of postoperative complications and mortality.$^{6-8}$ Moreover, blood loss, postoperative poor appetite, and poor food intake occur regularly among elderly patients in hospital. ${ }^{9-11}$ Therefore, clinicians are seeking effective measures which can improve the perioperative nutritional status of elderly patients after hip surgery. ${ }^{12-14}$

Among various nutritional supplement interventions, many studies have proposed that oral nutritional supplementation (ONS) might be a convenient method to enhance energy and protein intake and be beneficial for elderly patients who are undergoing trauma stress reaction from hip fractures or surgeries to improve bowel health and nutrient intake. Furthermore, ONS is more economical and practical than parenteral nutritional supplementation. ${ }^{15,16}$ One multicenter, randomized controlled trial (RCT),
Correspondence: Zhou Xiang Department of Orthopedics, West China Hospital, Sichuan University, Chengdu, 6I004I Sichuan Province, People's Republic of China

Email xiangzhoul5@hotmail.com 
which mainly investigated the cost-effectiveness of intensive nutritional supplementation, found that the cost of oral nutritional intervention is lower than that of other types of nutritional intervention. Meanwhile, cost-effectiveness evaluation showed that the ONS intervention route is more likely to be cost-effective. ${ }^{16}$

While ONS has been increasingly attracting the attention of clinicians, more and more RCTs have been conducted to evaluate the effectiveness of ONS for elderly patients after hip surgery and suggest that ONS is a beneficial intervention for elderly patients after hip surgery to improve the nutritional status. ${ }^{9,12,13,17,18}$ However, there remain opposing opinions about the efficiency of ONS. Some researchers have shown that functional recovery and mortality were not statistically improved after ONS intervention in elderly patients after hip surgery, ${ }^{19-21}$ while a relevant review mentioned that a definite conclusion about ONS for elderly patients with hip fracture, whether surgery was performed or not, could not be drawn because of weak evidence. ${ }^{20}$

As orthopedic doctors, we are concerned about the management of nutritional status of elderly patients during the perioperative period. Obviously, we wish to have better knowledge about appropriate interventions to reduce complications, shorten the time of hospitalization, and improve the patients' health. Therefore, the aim of this meta-analysis was to determine whether ONS can be recommended as a routine nutritional intervention for elderly patients after hip surgery.

\section{Clinical relevance}

It is very important to return the nutritional status back to normal levels in elderly patients aged over 65 years during the perioperative period. Meanwhile, strategy selection should be evidence based. The findings of this meta-analysis on whether perioperative ONS can reduce complications are clinically relevant for clinicians, including emergency physicians, orthopedic surgeons, nursing staff, geriatricians, and rehabilitation physicians, and can help them properly treat elderly patients and effectually improve clinical outcomes.

\section{Materials and methods \\ Data sources and searches}

We searched for relevant articles published up to May 2014 in databases including PubMed, Embase, and the Cochrane Central Register of Controlled Trials. The terms "oral nutrition" or "oral supplement", "hip surgery" or "hip fracture" or "femoral neck fracture" or "intertrochanteric fracture" or "subtrochanteric fracture", and "old" or "elderly" or "aged" were used to search titles, abstracts, and medical subject headings. We also browsed the reference lists and consulted experts to search for potentially eligible studies.

\section{Study identification}

The inclusion criteria used in the selection were as follows: 1) target population: patients aged over 65 years who had had hip fractures (femoral neck, intertrochanteric or subtrochanteric, acetabulum fractures) and undergone surgery (open reduction and internal fixation or arthroplasty); 2) intervention measure: perioperative ONS (orally taking high-calorie or high-protein diets); and 3) design type: RCT. The exclusion criteria used in the selection were: 1) patients with multiple systemic fractures or pathologic fractures; 2) data without standard deviations; 3) participants with hip fractures who had undergone nonsurgical treatment.

\section{Quality assessment}

We assessed the quality of individual studies by using the validated Oxford Scale and obtaining Jadad scores, ${ }^{22}$ which ranged from 1-5 points. Scores of 1-2 were considered as low quality, while scores of 3-5 were considered as high quality. Two independent reviewers performed the initial screening and extraction procedures. Then, another two investigators independently assessed all articles which met the inclusion criteria. Whenever there was a disagreement, it was solved by collective discussion among the investigators. ${ }^{23}$

\section{Main outcomes}

We extracted information about the characteristics of the included studies, such as the research design, population of participants, age of participants, fracture classification, follow-up periods, intervention measurements, control measurements, and the assessment criteria. Then, we analyzed each study for its Jadad score.

Data were collected from the included studies, including data for: 1) total protein; 2) complications (including all infections, bed sores, cardiac disease, cognitive impairment, prolonged immobilization, thrombophlebitis, deep vein thrombosis, vomiting, diarrhea, pressure ulcers, dysphasia, severe hyponatremia, anaphylaxis, pneumonedema, pulmonary embolism, and myocardial infarction); 3 ) change in serum albumin levels (the difference in serum albumin levels before and after intervention $[\mathrm{g} / \mathrm{L}])$; and 4) mortality.

\section{Data synthesis}

Perioperative data regarding the patients, interventions, and outcomes mentioned above were extracted from the 
included studies. We used Review Manager 5.1 software to analyze the data and adopted a $95 \%$ confidence interval (CI). Two reviewers monitored the data inputting to ensure accuracy. For the measurement outcomes, the mean standard deviation, and $n$ were recorded, and the standard mean difference (SMD) was calculated. For the enumeration outcomes, the scale and the numbers were recorded, then the odds ratio (OR) was calculated. ${ }^{24,25}$

\section{Heterogeneity, sensitivity, and risk of bias}

We used $I^{2}$ to test heterogeneity and estimate total variation across studies. For $I^{2}$, values between $25 \%$ and $50 \%$ were considered as low heterogeneity; those between $50 \%$ and $75 \%$ were considered as medium heterogeneity; and those over $75 \%$ were considered as high heterogeneity. ${ }^{23,24,26} \mathrm{We}$ qualitatively assessed each included study for allocation, attrition, and reporting bias, using Stata 11 software to perform the Begg's test. ${ }^{23,27-29}$

\section{Results Characteristics of included studies}

As shown in Figure 1, 57 articles published from 1966 to May 2014 were retrieved. Following the inclusion and exclusion criteria, we eliminated the retrospective studies with historical control, the studies lacking original data or standard deviation analysis, and the research with different evaluation indicators. After reading the full texts, we eliminated the studies that were not RCTs, not full text or relevant to ONS or standard deviation. Finally, ten RCTs ${ }^{13,14,19,21,30-35}$ were included; the characteristics of these studies are presented in Table 1. A total of 986 elderly patients who had undergone hip surgery and were aged over 65 years were included. Each of the ten studies was an RCT, and two of them were double blind. ${ }^{19,33}$ Further, they all used standard deviation to analyze results. ${ }^{23}$ The study quality varied across these trials: six of the ten included studies had Jadad scores of 3-5, while the other four studies scored 1-2.

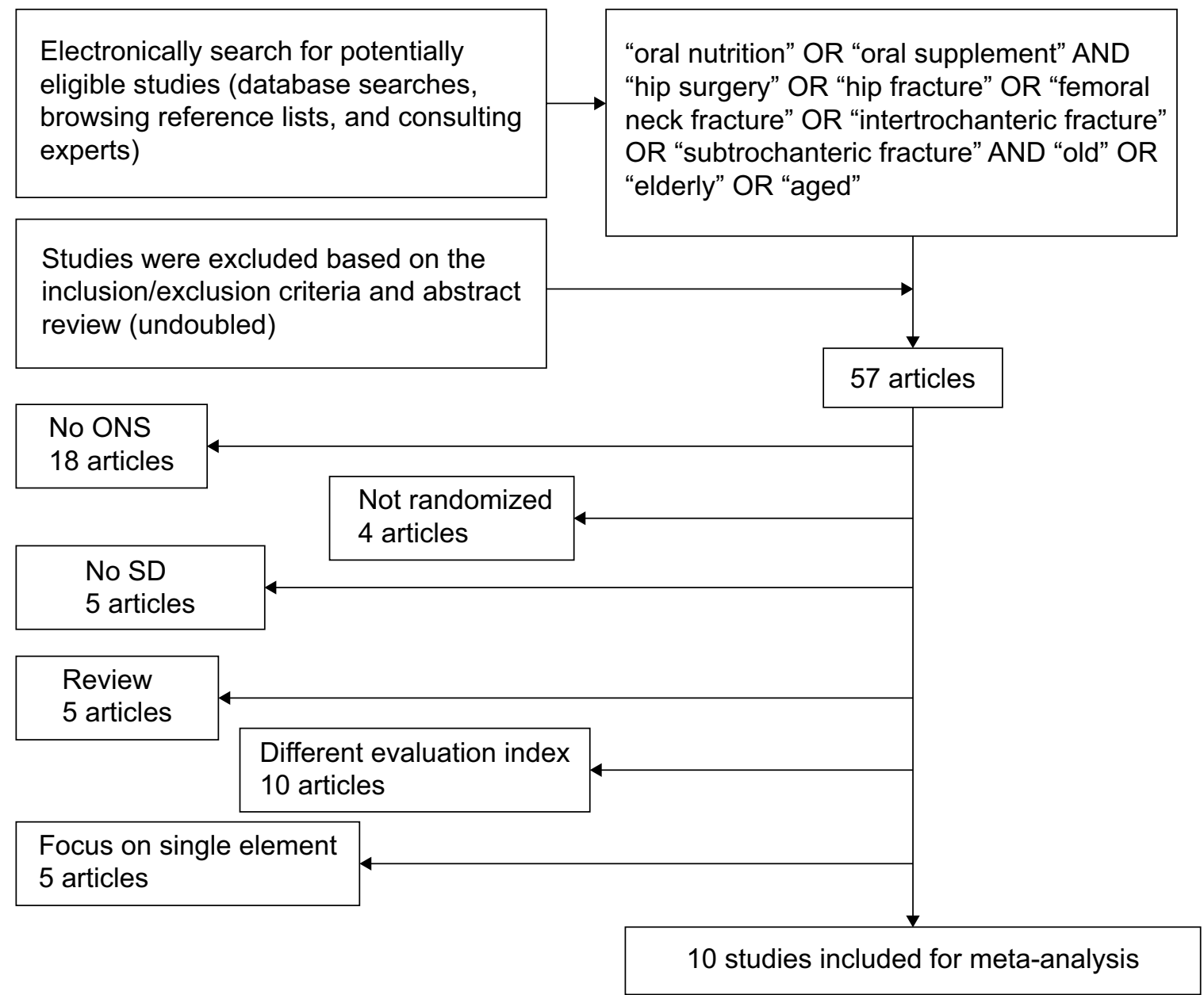

Figure I Flow diagram of the selection of studies.

Notes: The flow diagram expounds the studies identified, included, and excluded, as well as the reasons for exclusion. Ten studies were included. Abbreviations: ONS, oral nutritional supplementation; SD, standard deviation. 


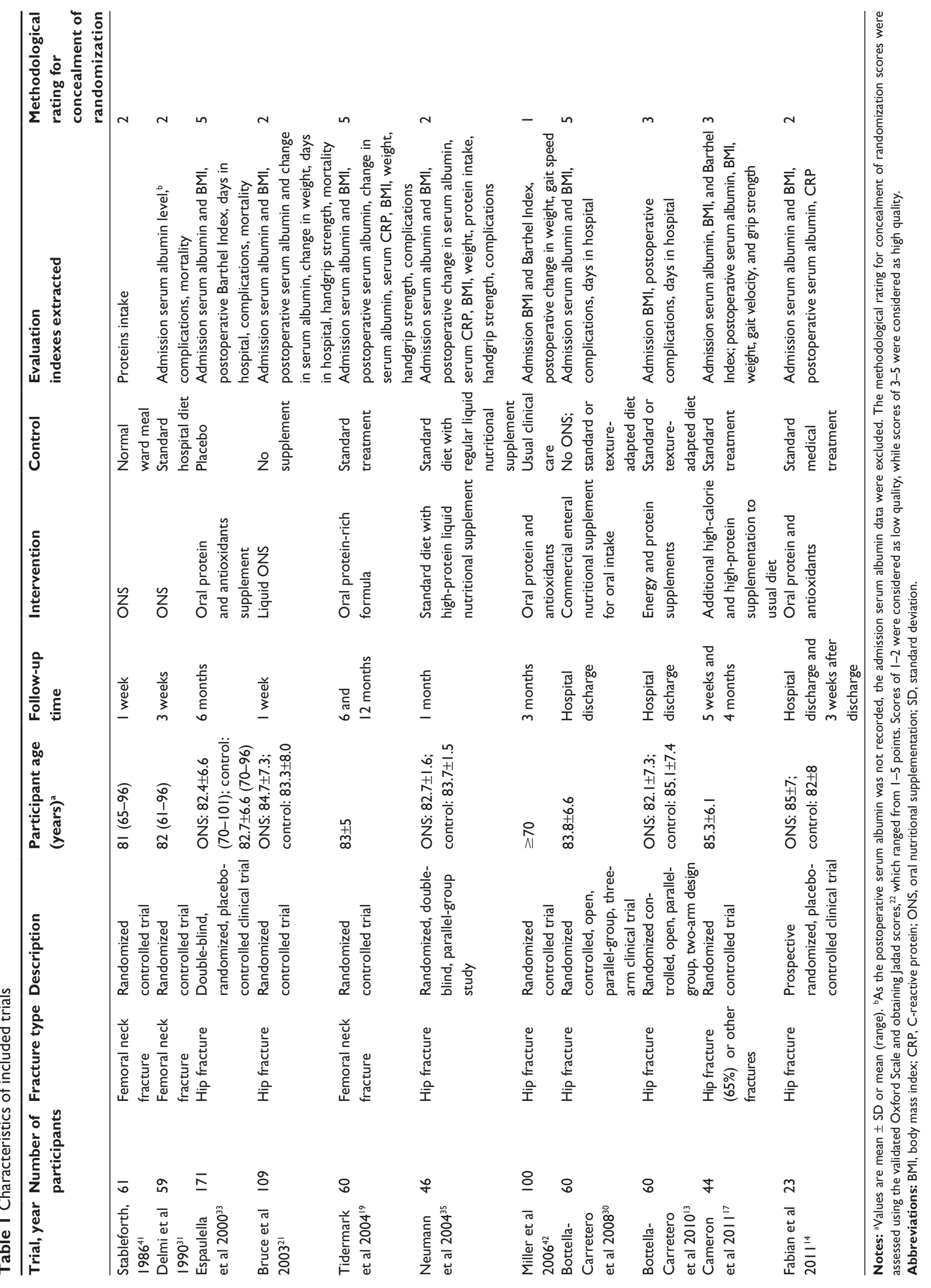




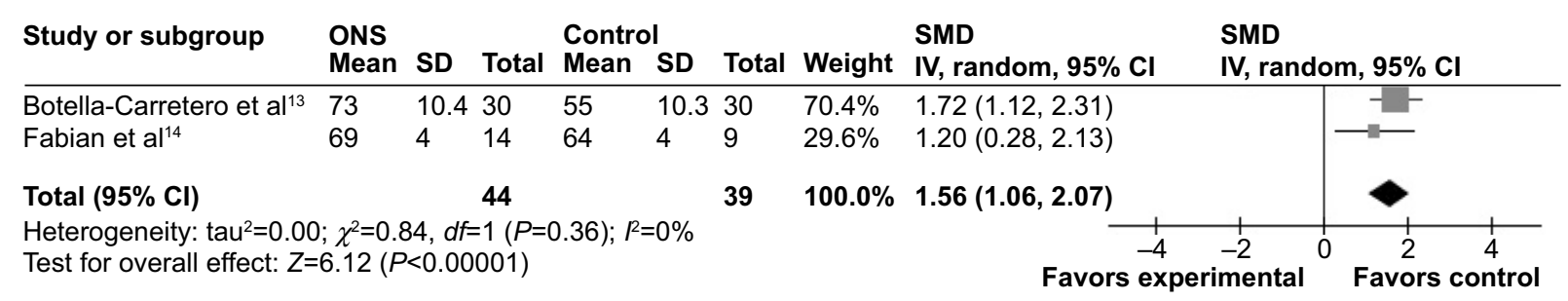

Figure 2 Forest plot for total proteins.

Notes: A random effects analysis model was adopted. The forest plot indicates that there was a significant increase in total protein levels at discharge for the ONS group compared to the control (SMD: 1.56 [95\% Cl: I.06, 2.07]; $P<0.0000 \mathrm{I}$ ). Heterogeneity: $I^{2}=0 \% ; P=0.36$.

Abbreviations: $\mathrm{Cl}$, confidence interval; $d f$, degrees of freedom; IV, intravenous; ONS, oral nutritional supplementation; SD, standard deviation; SMD, standard mean difference.

As shown in Table 1, we extracted information about the research design characteristics of the included studies, including the population of participants, age of participants, fracture classification, follow-up period, intervention measurements, control measurements, the comparison of assessment criteria between control group and intervention group, and the Jadad score of each study. Not all evaluation indicators of the included studies were the same, so we merged the data of those studies with the same evaluation indicator to analyze the results.

\section{Total protein}

Following the inclusion and exclusion criteria, two studies (Bottella-Carretero et $\mathrm{al}^{13}$ and Fabian et $\mathrm{al}^{14}$ ) were included. The two studies had a total of 83 patients in the meta-analysis, consisting of 44 patients in the ONS group and 39 in the control group. There was a statistically significant increase of the total protein levels in ONS group before patients were discharged (SMD $=1.56$ [95\% CI: 1.06, 2.07]; $P<0.00001$ ) (Figure 2). There was no evidence of heterogeneity between the studies $\left(I^{2}=0 \% ; P=0.36\right)$.

\section{Complications}

Following the inclusion and exclusion criteria, six studies (Tidermark et al, ${ }^{19}$ Neumann et al, ${ }^{35}$ Espaulella et al, ${ }^{33}$ Delmi et $\mathrm{al}^{31}$ and Bottella-Carretero et $\mathrm{al}^{13,30}$ ) were included in the complications meta-analysis. A total of 463 patients from the six studies were included in the meta-analysis, consisting of 220 patients in the ONS group and 243 in the control group. Figure 3 shows that the ONS had a measurable effect on reducing complications after hip surgery in elderly patients ( $\mathrm{OR}=0.49$ [ $95 \%$ CI: $0.32,0.73] ; P=0.0005)$. No evidence of statistical significance for heterogeneity was found among the studies $\left(I^{2}=27 \% ; P=0.24\right)$.

\section{Wound infection}

Following the inclusion and exclusion criteria, three studies (Bottella-Carretero et al, ${ }^{13}$ Delmi et $a^{31}$ and Neumann et a ${ }^{35}$ ) were included in the wound infection meta-analysis. A total of 199 patients from the three studies were included in the meta-analysis, consisting of 97 patients in the ONS group and 102 in the control group. Pooled results indicate that the ONS group had a lower rate of wound infection than

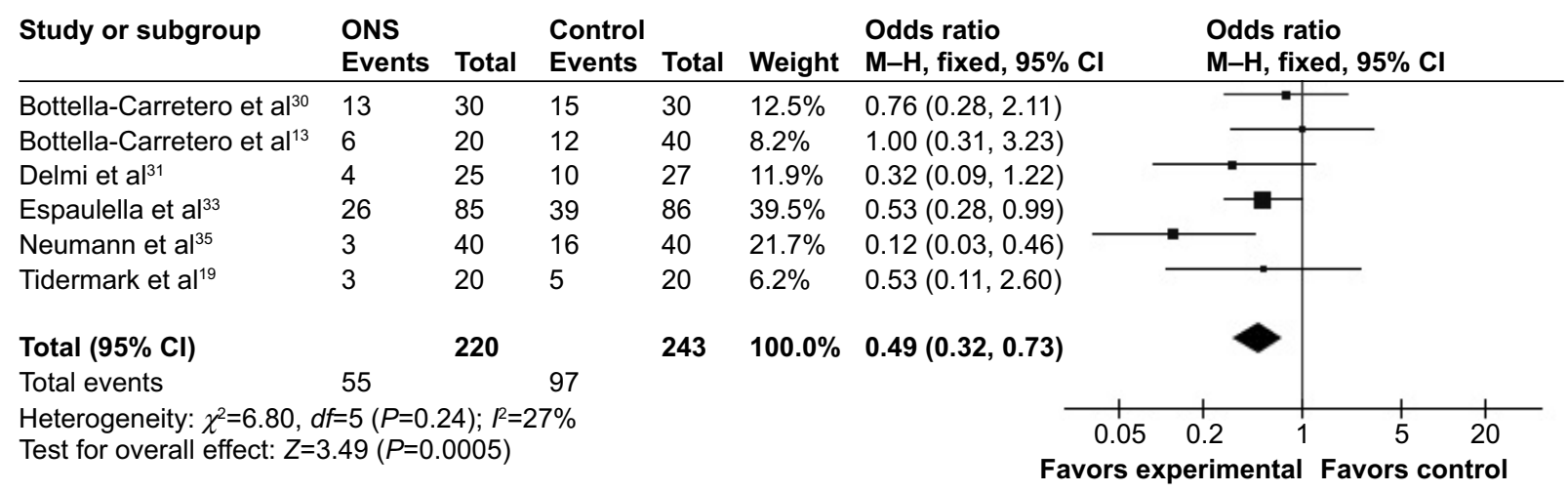

Figure 3 Forest plot for complications.

Notes: This forest plot displays the odds ratios of complications estimated from six cohort studies. The combined data indicate that there were fewer complications in the intervention group compared to the control ( $\mathrm{OR}=0.49$ [ $95 \% \mathrm{Cl}: 0.32,0.73$ ]; $P=0.0005$ ). Heterogeneity: $I^{2}=27 \% ; P=0.24$.

Abbreviations: $\mathrm{Cl}$, confidence interval; $d f$, degrees of freedom; ONS, oral nutritional supplementation; OR, odds ratio; $M-H, M a n t e l-H a e n s z e l$. 


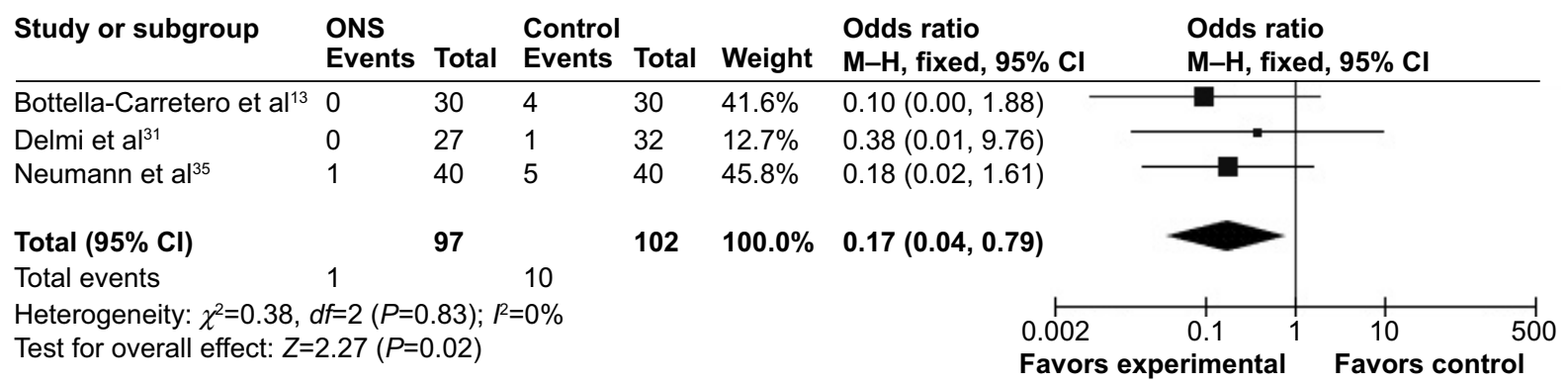

Figure 4 Forest plot for wound infections.

Notes: The forest plot shows the odds ratios of wound infections estimated from three studies. The combined data indicate that there were fewer wound infections in the ONS group compared to the control (OR $=0.17$ [ $95 \% \mathrm{Cl}: 0.04,0.79$ ]; $P=0.02)$. Heterogeneity: $I^{2}=0 \% ; P=0.83$.

Abbreviations: $\mathrm{Cl}$, confidence interval; $d f$, degrees of freedom; ONS, oral nutritional supplementation; $\mathrm{M}-\mathrm{H}$, Mantel-Haenszel.

the control group (OR $=0.17$ [95\% CI: 0.04, 0.79]; $P=0.02)$. There was no evidence of heterogeneity among the studies $\left(I^{2}=0 \%, P=0.83\right)$ (Figure 4).

\section{Respiratory infection}

Following the inclusion and exclusion criteria, three studies (Bottella-Carretero et al, ${ }^{30}$ Delmi et $\mathrm{al}^{31}$ and Neumann et $\mathrm{al}^{35}$ ) were included in the respiratory infection meta-analysis. A total of 200 patients from the three studies were included in the meta-analysis, consisting of 100 patients in the ONS group and 100 in the control group. Figure 5 shows the respiratory infection rates between ONS patients and the control group. According to the three trials included, there were significant statistical difference in the baseline and the length of hospitalization between two groups (OR $=0.26$ [95\% CI: 0.07, $0.94] ; P=0.04)$. No statistical significance of heterogeneity was found among the included studies $\left(I^{2}=21 \% ; P=0.28\right)$.

\section{Urinary tract infection}

Following the inclusion and exclusion criteria, three studies (Bottella-Carretero et al, ${ }^{30}$ Delmi et $\mathrm{al}^{31}$ and Neumann et $\mathrm{al}^{35}$ ) were included in the urinary tract infection meta-analysis. A total of 200 patients from the three studies were included in the meta-analysis. Figure 6 shows the urinary tract infection rates between ONS patients and the control group. Based on the three trials, there were significant differences between the two groups both on baseline and hospitalization time $(\mathrm{OR}=0.22$ [95\% CI: $0.05,0.90] ; P=0.03)$. There was no evidence for heterogeneity among the studies $\left(I^{2}=0 \% ; P=0.90\right)$.

\section{Change in serum albumin}

Following the inclusion and exclusion criteria, data for the change in serum albumin levels from three studies (Bruce et $\mathrm{al},{ }^{21}$ Neumann et $\mathrm{al}^{35}$ and Tidermark et $\mathrm{al}^{19}$ ) were included. These three studies had a total of 172 patients, consisting of 82 patients in the ONS group and 90 in the control group in the meta-analysis. As shown in Figure 7, the change in serum albumin did not have any statistically significant difference between ONS patients and control group (SMD $=0.82[95 \%$ $\mathrm{CI}:-1.47,3.10] ; P=0.48)$. Heterogeneity was found to be large and statistically significant for the change in serum albumin in this analysis $\left(I^{2}=97 \%, P<0.00001\right)$.

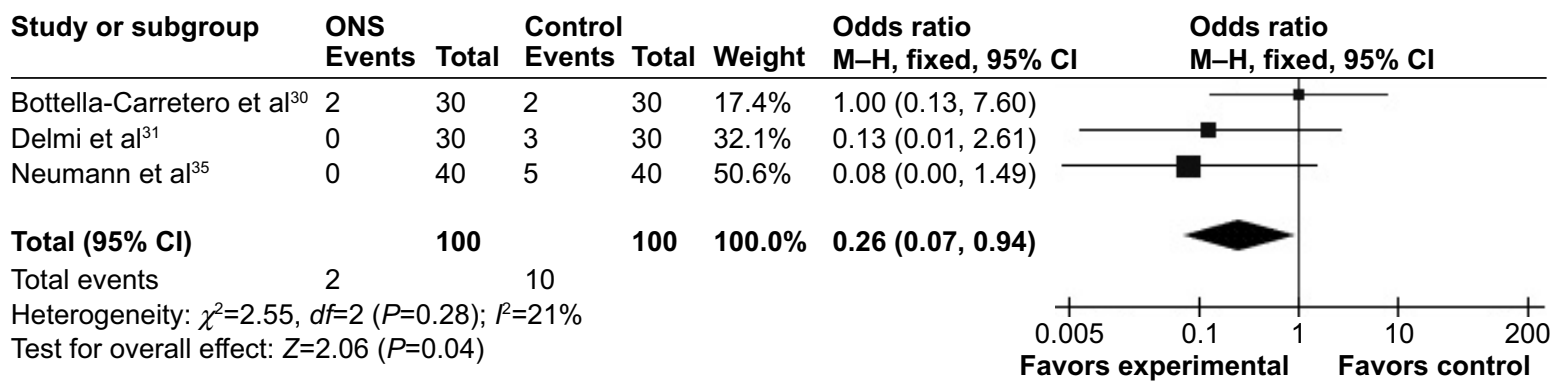

Figure 5 Forest plot for respiratory infections.

Notes: The forest plot shows the odds ratios of respiratory infections estimated from three studies. The combined data indicate that there were fewer respiratory infections in the ONS group compared to the control (OR =0.26 [95\% Cl: 0.07, 0.94]; $P=0.04)$. Heterogeneity: $I^{2}=21 \% ; P=0.28$.

Abbreviations: $\mathrm{Cl}$, confidence interval; $d f$, degrees of freedom; ONS, oral nutritional supplementation; M-H, Mantel-Haenszel. 


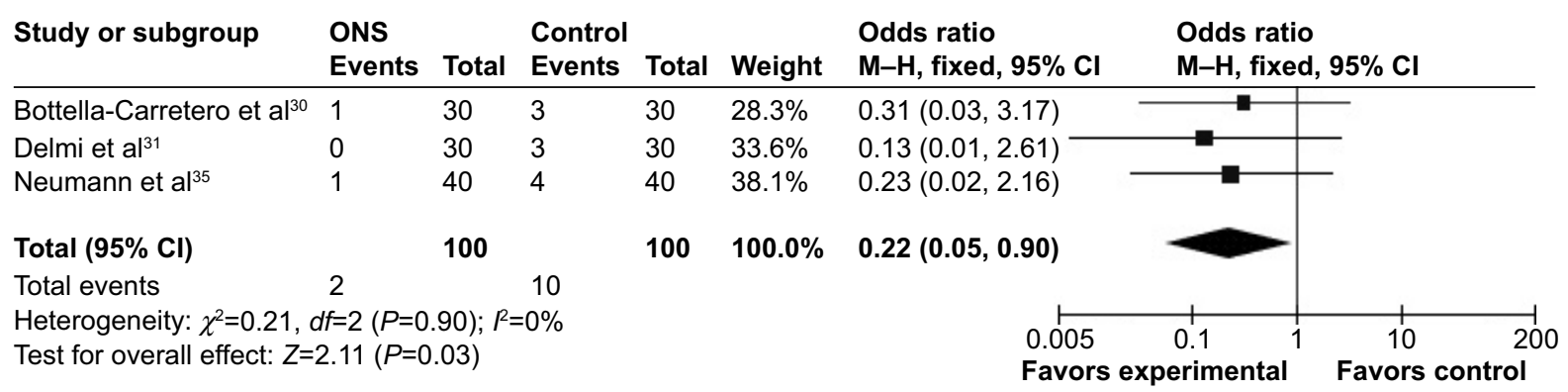

Figure 6 Forest plot for urinary tract infections.

Notes: The forest plot shows the odds ratios of urinary tract infections estimated from three studies. The combined data indicate that there were fewer urinary tract infections in the ONS group compared to the control (OR $=0.22$ [ $95 \% \mathrm{Cl}: 0.05,0.90] ; P=0.03)$. Heterogeneity: $I^{2}=0 \% ; P=0.90$.

Abbreviations: $\mathrm{Cl}$, confidence interval; $d f$, degrees of freedom; ONS, oral nutritional supplementation; $\mathrm{M}-\mathrm{H}$, Mantel-Haenszel.

\section{Mortality}

Following the inclusion and exclusion criteria, five studies (Bruce et al, ${ }^{21}$ Delmi et al, ${ }^{31}$ Espaulella et al, ${ }^{33}$ Neumann et $\mathrm{al}^{35}$ and Tidermark et $\mathrm{al}^{19}$ ) were included. The five studies had a total of 416 patients, consisting of 198 patients in the ONS group and 218 in the control group in the metaanalysis. The analysis of mortality indicated that ONS had no statistically significant effect on mortality (ONS group $35 / 198$ versus control group 39/218; OR $=1.02$ [95\% CI: $0.62,1.70] ; P=0.93)$. Large and statistically significant heterogeneity was found in this meta-analysis $\left(I^{2}=34 \%\right.$; $P=0.19$ ) (Figure 8).

\section{Assessment of publication bias}

As shown in Figure 9, the Begg's funnel plot shows no significant Begg's test for publication bias $(P>0.05)$, indicating no evidence of publication bias among the studies.

\section{Discussion}

To our knowledge, this is the first meta-analysis assessing studies about elderly patients receiving ONS after hip surgery. The overall results of the current investigation suggest that ONS improves early recovery by increasing the total protein level and reducing complications in elderly patients after hip surgery.

As shown in our meta-analysis, there was a statistically significant improvement in the serum total protein level in the ONS group compared with that in the control group. As a nutritional marker, serum total protein, along with nutritionrich supplements, helps patients to recover more quickly. Moreover, protein-rich supplementation might further lower blood pressure, improve lipid levels, and reduce estimated cardiovascular risks. ${ }^{36}$

Complications are always directly related to the quality of the patient's lifestyle and the quality of medical services. The incidence of complications (eg, pressure sores, infections, deep venous thromboses, cardiovascular events) in elderly patients after hip surgery is high and deserves more attention. Our study showed the complications rate was lower in elderly patients receiving ONS than in the control group. Similar results were found in previous studies of nasogastric feeding and parenteral nutrition. ${ }^{13,19,30,31,33,37}$ Further, we carried out a subgroup analysis on infections (including wound infection, respiratory tract infection, and urinary tract infection), the results of which showed a consistent reduction in each infection rate in the ONS group. The wound infection rate

\begin{tabular}{|c|c|c|c|c|c|c|c|c|c|}
\hline Study or subgroup & $\begin{array}{l}\text { ONS } \\
\text { Mean }\end{array}$ & SD & Total & $\begin{array}{l}\text { Contro } \\
\text { Mean }\end{array}$ & SD & Total & Weight & $\begin{array}{l}\text { SMD } \\
\text { IV, random, } 95 \% \mathrm{Cl}\end{array}$ & $\begin{array}{l}\text { SMD } \\
\text { IV, random, } 95 \% \mathrm{CI}\end{array}$ \\
\hline Bruce et $\mathrm{al}^{21}$ & 4.1 & 0.7 & 50 & 5.3 & 1 & 59 & $34.6 \%$ & $-1.36(-1.78,-0.94)$ & 단 \\
\hline Neumann et al ${ }^{35}$ & 7 & 1.3 & 14 & 2 & 1.3 & 14 & $31.5 \%$ & $3.73(2$. & \\
\hline Tidermark et $\mathrm{al}^{19}$ & 6.5 & 3.7 & 18 & 4.7 & 6.7 & 17 & $34.0 \%$ & $0.33(-$ & \\
\hline Total $(95 \% \mathrm{Cl})$ & & & 82 & & & 90 & $100.0 \%$ & $0.82(-1.47,3.10)$ & \\
\hline \multicolumn{8}{|c|}{$\begin{array}{l}\text { Heterogeneity: } \text { tau }^{2}=3.89 ; \chi^{2}=63.43, d f=2(P=0.00001) ; P^{2}=97 \% \\
\text { Test for overall effect: } Z=0.70(P=0.48)\end{array}$} & Favor & $\begin{array}{ccccc}-4 & -2 & 0 & 2 & 4 \\
\text { perimental } & \text { Favors }\end{array}$ \\
\hline
\end{tabular}

Figure 7 Forest plot for changes in serum albumin.

Notes: A random effects model was adopted. This forest plot indicates that there was no statistical improvement in change in serum albumin levels between the ONS intervention group and the control (SMD: 0.82 [95\% Cl: $-1.47,3.10] ; P=0.48$ ). Heterogeneity: $I^{2}=97 \% ; P<0.00001$.

Abbreviations: $\mathrm{Cl}$, confidence interval; $d f$, degrees of freedom; IV, intravenous; ONS, oral nutritional supplementation; SD, standard deviation; SMD, standard mean difference. 


\begin{tabular}{|c|c|c|c|c|c|c|c|c|}
\hline Study or subgroup & $\begin{array}{l}\text { ONS } \\
\text { Events }\end{array}$ & Total & $\begin{array}{l}\text { Control } \\
\text { Events }\end{array}$ & Total & Weight & $\begin{array}{l}\text { Odds ratio } \\
\mathrm{M}-\mathrm{H} \text {, fixed, } 95 \% \mathrm{Cl}\end{array}$ & $\begin{array}{l}\text { Odds ratio } \\
\mathrm{M}-\mathrm{H} \text {, fixed, } 95 \% \mathrm{Cl}\end{array}$ & \\
\hline Bruce et $\mathrm{al}^{21}$ & 11 & 50 & 14 & 59 & $34.1 \%$ & $0.91(0.37,2.23)$ & 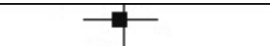 & \\
\hline Delmi et $\mathrm{al}^{31}$ & 6 & 27 & 10 & 32 & $24.2 \%$ & $0.63(0.19,2.04)$ & & \\
\hline Espaulella et $a^{33}$ & 17 & 61 & 10 & 67 & $23.4 \%$ & $2.20(0.92,5.28)$ & & \\
\hline Neumann et al ${ }^{35}$ & 0 & 40 & 4 & 40 & $15.1 \%$ & $0.10(0.01,1.92)$ & & \\
\hline Tidermark et al ${ }^{19}$ & 1 & 20 & 1 & 20 & $3.2 \%$ & $1.00(0.06,17.18)$ & & \\
\hline Total (95\% Cl) & & 198 & & 218 & $100 \%$ & $1.02(0.62,1.70)$ & & \\
\hline Total events & 35 & & 39 & & & & & \\
\hline \multicolumn{4}{|c|}{$\begin{array}{l}\text { Heterogeneity: } \chi^{2}=6.06, d f=4(P=0.19) ; P^{2}=34 \% \\
\text { Test for overall effect: } Z=0.09(P=0.93)\end{array}$} & & & 0.005 & 0.1 & 200 \\
\hline
\end{tabular}

Figure 8 Forest plot for mortality.

Notes: This forest plot shows the odds ratios of mortality. The combined data indicate that there was no statistically significant difference in mortality rates between the ONS intervention group and the control (OR =I.02 [95\% Cl: $0.62 ; 1.70] ; P=0.93)$. Heterogeneity: $I^{2}=34 \% ; P=0.19$.

Abbreviations: $\mathrm{Cl}$, confidence interval; $\mathrm{df}$, degrees of freedom; ONS, oral nutritional supplementation; $\mathrm{M}-\mathrm{H}$, Mantel-Haenszel.

showed that ONS had a positive effect on wound healing. The decreased infection rates observed in the ONS group could be related to the increased serum total protein level, which would benefit the elderly patients to maintain the immunological functions. ${ }^{38}$ ONS had a positive effect on the respiratory infection rate as well as the wound infection rate. Furthermore, high-protein and high-calorie diets have been shown to reduce the urinary tract infection rate. ${ }^{39}$

As an independent prognostic factor for elderly patients after hip surgery, serum albumin is an important index for assessing rehabilitation after surgery. ${ }^{40} \mathrm{~A}$ change in serum albumin levels before and after ONS was observed in the present study. The merged data from three trials about the change in serum albumin showed no statistically significant difference (Figure 7), ${ }^{19,21,35}$ while there was significant heterogeneity $\left(\chi^{2}=63.43, d f=2[P<0.00001] ; I^{2}=97 \%\right)$ was found using the random effects model. Further research should aim to define whether ONS can influence the serum albumin levels.

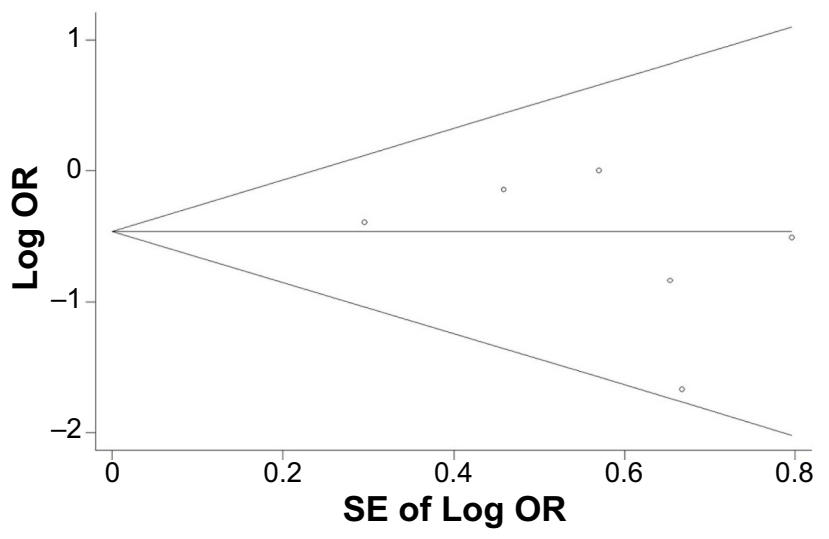

Figure 9 Begg's funnel plot for publication bias with pseudo $95 \%$ confidence limits. Note: The presence of publication bias in studies comparing complications rates between ONS patients and controls was investigated using Begg's funnel plot. Abbreviation: SE, standard error.
Our mortality data indicate that there were no statistical differences between the ONS group and the control group. This finding is consistent with previous studies. ${ }^{20,21,33}$ However, more attention should be paid to one important element: unavoidable death. The differences in mortality between the ONS group and the control group were not statistically significant because inevitable deaths were not excluded. Approximately one-quarter (28\%) of deaths after hip surgery in the elderly are unavoidable regardless of the perioperative care regimen. ${ }^{8}$ The mortality rates of the two groups in the present study are both below one-quarter (ONS group: $35 / 198 \approx 17.68 \%$; control group: $39 / 218 \approx 17.89 \%$ ). Thus, it is inadvisable to draw the conclusion that the use of ONS in elderly patients after hip surgery has no proven effect on mortality according to Figure 8. Among the included studies, three studies had follow-up within 1 month; three within 4 months; one within 6 months; one at both 6 months and 12 months; and the other three followed-up only on the day of discharge (Table 1). Further large and high-quality randomized trials are needed to confirm these findings showing the unavoidable deaths of some patients.

The main limitations of this review were the small number of available studies and the gap between the follow-up times of included studies. When the publication bias was adjusted and each study was excluded from the model once, all the significant results observed remained valid. We found no evidence of existing publication bias. Moreover, data about the types, quantities, compositions, and timing of nutritional supplementation at any stage were not reported in any of the included studies.

\section{Conclusion}

The results from this meta-analysis suggest that perioperative ONS for elderly patients after hip surgery promotes early 
rehabilitation with reduced complications and decreased infection rate. Because of the high heterogeneity, it is unclear whether perioperative ONS has an effect on increasing serum albumin levels or reducing mortality. More high-quality investigations are needed for further detailed study.

\section{Acknowledgment}

This work was supported by the National Natural Sciences Foundation of China (grant numbers 81401813 and 31370984).

\section{Disclosure}

The authors report no conflicts of interest in this work.

\section{References}

1. Stevens JA, Rudd RA.The impact of decreasing U.S. hip fracture rates on future hip fracture estimates. Osteoporos Int. 2013;24(10): 2725-2728.

2. Harvey N, Dennison E, Cooper C. Osteoporosis: impact on health and economics. Nat Rev Rheumatol. 2010;6:99-105.

3. Johnell O, Kanis J. Epidemiology of osteoporotic fractures. Osteoporos Int. 2005;16 Suppl 2:S3-S7.

4. Kanis J, Odén A, McCloskey E, Johansson H, Wahl D, Cooper C; IOF Working Group on Epidemiology and Quality of Life. A systematic review of hip fracture incidence and probability of fracture worldwide. Osteoporos Int. 2012;23(9):2239-2256.

5. Cheng SY, Levy AR, Lefaivre KA, Guy P, Kuramoto L, Sobolev B. Geographic trends in incidence of hip fractures: a comprehensive literature review. Osteoporos Int. 2011;22(10):2575-2586.

6. Bachrach-Lindström M, Johansson T, Unosson M, Ek AC, Wahlström O. Nutritional status and functional capacity after femoral neck fractures: a prospective randomized one-year follow-up study. Aging (Milano). 2000;12:366-374.

7. McMurdo ME, Witham MD, Gillespie ND. Including older people in clinical research. BMJ. 2005;331:1036-1037.

8. Foss NB, Kehlet H. Mortality analysis in hip fracture patients: implications for design of future outcome trials. Br J Anaesth. 2005; 94:24-29.

9. Pirlich M, Schütz T, Norman K, et al. The German hospital malnutrition study. Clin Nutr. 2006;25:563-572.

10. Rasmussen HH, Kondrup J, Staun M, Ladefoged K, Kristensen H, Wengler A. Prevalence of patients at nutritional risk in Danish hospitals Clin Nutr. 2004;23:1009-1015.

11. Bruun LI, Bosaeus I, Bergstad L, Nygaard K. Prevalence of malnutrition in surgical patients: evaluation of nutritional support and documentation. Clin Nutr. 1999;18:141-147.

12. Mak JC, Cameron ID, March LM; National Health and Medical Research Council. Evidence-based guidelines for the management of hip fractures in older persons: an update. Med J Aust. 2010;192: $37-41$.

13. Botella-Carretero JI, Iglesias B, Balsa JA, Arrieta F, Zamarrón I, Vázquez C. Perioperative oral nutritional supplements in normally or mildly undernourished geriatric patients submitted to surgery for hip fracture: a randomized clinical trial. Clin Nutr. 2010;29:574-579.

14. Fabian E, Gerstorfer I, Thaler HW, Stundner H, Biswas P, Elmadfa I. Nutritional supplementation affects postoperative oxidative stress and duration of hospitalization in patients with hip fracture. Wien Klin Wochenschr. 2011;123:88-93.

15. Price R, Daly F, Pennington CR, McMurdo ME. Nutritional supplementation of very old people at hospital discharge increases muscle strength: a randomised controlled trial. Gerontology. 2005;51:179-185.
16. Wyers CE, Reijven PL, Evers SM, et al. Cost-effectiveness of nutritional intervention in elderly subjects after hip fracture. A randomized controlled trial. Osteoporos Int. 2012;24(1):151-162.

17. Cameron ID, Kurrle SE, Uy C, Lockwood KA, Au L, Schaafsma FG. Effectiveness of oral nutritional supplementation for older women after a fracture: rationale, design and study of the feasibility of a randomized controlled study. BMC Geriatr. 2011;11:32.

18. Dwyer AJ, John B, Mam MK, Antony P, Abraham R, Joshi M. Relation of nutritional status to healing of compound fractures of long bones of the lower limbs. Orthopedics. 2007;30:709-712.

19. Tidermark J, Ponzer S, Carlsson S, et al. Effects of protein-rich supplementation and nandrolone in lean elderly women with femoral neck fractures. Clin Nutr. 2004;23:587-596.

20. Avenell A, Handoll HH. Nutritional supplementation for hip fracture aftercare in older people. Cochrane Database Syst Rev. 2010;(1):CD001880.

21. Bruce D, Laurance I, McGuiness M, Ridley M, Goldswain P. Nutritional supplements after hip fracture: poor compliance limits effectiveness. Clin Nutr. 2003;22:497-500.

22. Jadad AR, Moore RA, Carroll D, et al. Assessing the quality of reports of randomized clinical trials: is blinding necessary? Control Clin Trials. 1996;17:1-12.

23. Higgins JPT, Green S, editors. Cochrane Handbook for Systematic Reviews of Interventions. West Sussex: John Wiley \& Sons Ltd; 2008.

24. Higgins JP, Thompson SG, Deeks JJ, Altman DG. Measuring inconsistency in meta-analyses. BMJ. 2003;327:557-560.

25. Clarke M, Oxman A. Cochrane Reviewers'. Handbook 4.0 (updated July 1999). In: the Cochrane Liburay Issue 1. Oxford:Update Software; 2000.

26. Higgins JP, Thompson SG. Quantifying heterogeneity in a metaanalysis. Stat Med. 2002;21:1539-1558.

27. Harbord RM, Higgins JPT. Meta-regression in Stata. Stata J. 2008;8: 493-519.

28. DerSimonian R, Laird N. Meta-analysis in clinical trials. Control Clin Trials. 1986;7:177-188.

29. Begg CB. A measure to aid in the interpretation of published clinical trials. Stat Med. 2006;4:1-9.

30. Botella-Carretero JI, Iglesias B, Balsa JA, Zamarrón I, Arrieta F, Vázquez C. Effects of oral nutritional supplements in normally nourished or mildly undernourished geriatric patients after surgery for hip fracture: a randomized clinical trial. JPEN J Parenter Enteral Nutr. 2008;32:120-128.

31. Delmi M, Rapin CH, Bengoa JM, Delmas PD, Vasey H, Bonjour JP. Dietary supplementation in elderly patients with fractured neck of the femur. Lancet. 1990;335:1013-1016.

32. Eneroth M, Olsson UB, Thorngren KG. Nutritional supplementation decreases hip fracture-related complications. Clin Orthop Relat Res. 2006;451:212-217.

33. Espaulella J, Guyer H, Diaz-Escriu F, et al. Nutritional supplementation of elderly hip fracture patients. A randomized, double-blind, placebocontrolled trial. Age Ageing. 2000;29(5):425-431.

34. Duncan DG, Beck SJ, Hood K, Johansen A. Using dietetic assistants to improve the outcome of hip fracture: a randomised controlled trial of nutritional support in an acute trauma ward. Age Ageing 2006;35:148-153.

35. Neumann M, Friedmann J, Roy MA, Jensen GL. Provision of highprotein supplement for patients recovering from hip fracture. Nutrition. 2004;20:415-419.

36. Appel LJ, Sacks FM, Carey VJ, et al; OmniHeart Collaborative Research Group. Effects of protein, monounsaturated fat, and carbohydrate intake on blood pressure and serum lipids: results of the OmniHeart randomized trial. JAMA. 2005;294:2455-2464.

37. Hartgrink HH, Wille J, König P, Hermans J, Breslau PJ. Pressure sores and tube feeding in patients with a fracture of the hip: a randomized clinical trial. Clin Nutr. 1998;17:287-292.

38. Gaine WJ, Ramamohan NA, Hussein NA, Hullin MG, McCreath SW. Wound infection in hip and knee arthroplasty. J Bone Joint Surg Br. 2000;82:561-565. 
39. Wang YF, Yancy WS Jr, Yu D, Champagne C, Appel LJ, Lin PH. The relationship between dietary protein intake and blood pressure: results from the PREMIER study. J Hum Hypertens. 2008;22:745-754.

40. Symeonidis PD, Clark D. Assessment of malnutrition in hip fracture patients: effects on surgical delay, hospital stay and mortality. Acta Orthop Belg. 2006;72:420-427.
41. Stableforth PG. Supplement feeds and nitrogen and calorie balance following femoral neck fracture. Br J Surg. 1986;73(8):651-655.

42. Miller MD, Bannerman E, Daniels LA, Crotty M. Lower limb fracture, cognitive impairment and risk of subsequent malnutrition: a prospective evaluation of dietary energy and protein intake on an orthopaedic ward. Eur J Clin Nutr. 2006;60(7):853-861.

\section{Publish your work in this journal}

Clinical Interventions in Aging is an international, peer-reviewed journal focusing on evidence-based reports on the value or lack thereof of treatments intended to prevent or delay the onset of maladaptive correlates of aging in human beings. This journal is indexed on PubMed Central, MedLine,
CAS, Scopus and the Elsevier Bibliographic databases. The manuscript management system is completely online and includes a very quick and fair peer-review system, which is all easy to use. Visit http://www.dovepress. com/testimonials.php to read real quotes from published authors. 